\title{
Distinct Endocannabinoid Control of GABA Release at Perisomatic and Dendritic Synapses in the Hippocampus
}

\author{
Sang-Hun Lee, Csaba Földy, and Ivan Soltesz \\ Department of Anatomy and Neurobiology, University of California, Irvine, Irvine, California 92697-1280
}

\begin{abstract}
Endocannabinoid-mediated retrograde synaptic signaling is a key regulator of GABA release at synapses formed on the perisomatic region of pyramidal cells by basket cells that coexpress the cannabinoid type 1 receptor $\left(\mathrm{CB}_{1} \mathrm{R}\right)$ and cholecystokinin $(\mathrm{CCK})$. However, $\mathrm{CB}_{1} \mathrm{R}$ and CCK-positive GABAergic terminals are present on pyramidal cell dendrites as well, but the principles of endocannabinoid control of GABA release in dendrites are not understood. We performed paired recordings from CCK-positive perisomatically (basket cells) or dendritically projecting (Schaffer collateral-associated cells) interneurons and postsynaptic CA1 pyramidal cells to determine the properties of endocannabinoid signaling at GABAergic synapses along the somato-dendritic axis. Although several key elements of the currently known molecular machinery for endocannabinoid synthesis are thought be primarily localized in dendrites, our results revealed that the depolarization-induced suppression of inhibition, the endocannabinoid-mediated tonic inhibition of GABA release, and the metabotropic glutamate receptor activation-induced, $\mathrm{CB}_{1} \mathrm{R}$-mediated depression of $\mathrm{GABA}$ release were all significantly less effective at dendritic compared with perisomatic synapses. In addition, low concentration of exogenous $\mathrm{CB}_{1}$ receptor agonist inhibited GABA release to a lesser extent at dendritic compared with perisomatic synapses, indicating that presynaptic differences are partly responsible for the differential control of GABA release by endocannabinoids in dendrites. Together, these data demonstrate a novel domain-specific regulation of GABA release by endocannabinoid signaling in the hippocampus.
\end{abstract}

\section{Introduction}

Cannabinoids are lipid-derived messengers that modulate cognition, learning and memory, motor behavior, and pain perception (for recent review, see Heifets and Castillo, 2009; Kano et al., 2009). These behavioral effects are mediated by the $\mathrm{G}_{\mathrm{i} / \mathrm{o}}$-proteincoupled type 1 cannabinoid receptor $\left(\mathrm{CB}_{1} \mathrm{R}\right)$, which is thought to be among the most highly expressed G-protein-coupled receptors in the brain. In the rat hippocampus, $\mathrm{CB}_{1} \mathrm{Rs}$ are found at highest densities on the axon terminals and preterminal segments of cholecystokinin (CCK)-expressing GABAergic interneurons (Nyiri et al., 2005), in addition to the significantly lower $\mathrm{CB}_{1} \mathrm{R}$ expression levels exhibited by some excitatory terminals (Katona et al., 2006). The two major subtypes of $\mathrm{CB}_{1} \mathrm{R}$ - and CCKexpressing interneurons in the $\mathrm{CA} 1$ region of the hippocampus are the CCK-positive basket cells $\left(\mathrm{CCK}^{+} \mathrm{BCs}\right)$ that innervate the perisomatic region of pyramidal cells, and the also CCK-positive Schaffer collateral-associated cells $\left(\mathrm{CCK}^{+} \mathrm{SCAs}\right)$ that innervate the pyramidal cell dendrites in the radiatum and oriens layers (Cossart et al., 1998; Vida et al., 1998; Cope et al., 2002) (see also the "radial trilaminar cells" of Hájos and Mody, 1997; Elfant et al., 2008). Although there is considerable evidence concerning the various forms of endocannabinoid-mediated depression of

\footnotetext{
Received Dec. 14, 2009; revised April 18, 2010; accepted April 29, 2010.

This work was supported by National Institutes of Health Grant NS38580 (I.S.) and the Epilepsy Foundation through the generous support of the Eric W. Lothman Training Fellowship (S.-H.L.). We thank R. Zhu for technical assistance.

Correspondence should be addressed to Dr. Sang-Hun Lee, Department of Anatomy and Neurobiology, University of California, Irvine, Irvine, CA 92697-1280. E-mail: sanghun.lee@uci.edu.

DOI:10.1523/JNEUROSCI.6238-09.2010

Copyright $\odot 2010$ the authors $\quad 0270-6474 / 10 / 307993-08 \$ 15.00 / 0$
}

GABAergic transmission from $\mathrm{CCK}^{+}$BCs (Ohno-Shosaku et al., 2001; Wilson et al., 2001; Földy et al., 2006; Glickfeld and Scanziani, 2006), the nature of the endocannabinoid modulation of GABA release from SCAs is not yet understood.

The general question of how dendritic compared with somatic $\mathrm{CB}_{1} \mathrm{R}$-expressing GABAergic synapses are regulated by cannabinoid signaling is particularly interesting in light of the fact that the currently identified molecular machinery involved in the synthesis of endocannabinoids are primarily localized in pyramidal cell dendrites. Specifically, diacylglycerol lipase $\alpha$ (DGL $\alpha$ ), a key enzyme involved in the synthesis of $s n$ - 2 arachidonoyl glycerol (2-AG), the major endocannabinoid involved in depolarizationinduced suppression of inhibition (DSI) (Hashimotodani et al., 2007; Pan et al., 2009; Gao et al., 2010; Tanimura et al., 2010), has been shown to be expressed overwhelmingly in dendrites (Katona et al., 2006; Yoshida et al., 2006). In addition, metabotropic glutamate receptor 5 (mGluR5), which is involved in the metabotropic glutamate receptor-induced stimulation of endocannabinoid synthesis, is also more expressed at dendritic sites (Lujan et al., 1996). Furthermore, although previous in situ hybridization studies suggested a potentially lower expression of $\mathrm{CB}_{1} \mathrm{R}$ mRNA in interneurons with presumed dendritic projections (putative SCAs) (Marsicano and Lutz, 1999), a recent quantitative postembedding immunogold electron microscopy study using two distinct antibodies against $C_{1}$ Rs reported no differences in $C_{1} R$ density between somatic and dendritic GABAergic terminals (Nyiri et al., 2005).

Here, we used paired recordings from post hoc identified $\mathrm{CCK}^{+}$BCs and SCAs to determine whether the endocannabinoid-mediated control of GABA release differs between so- 
A

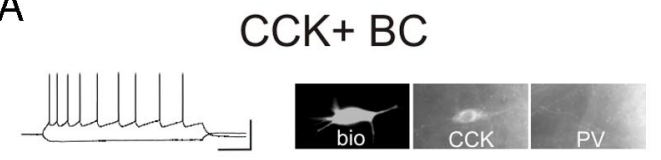

Str. L.-M.

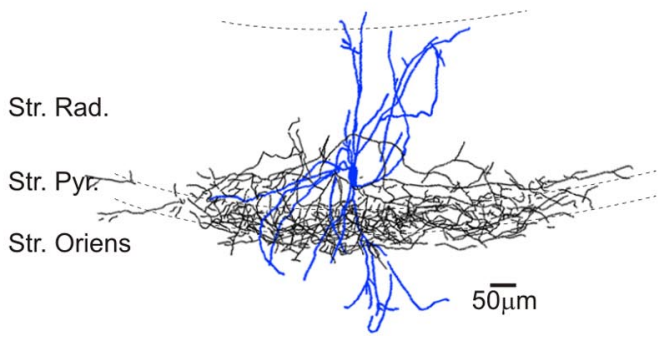

B

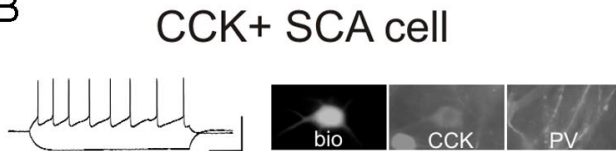

Str. L.-M.

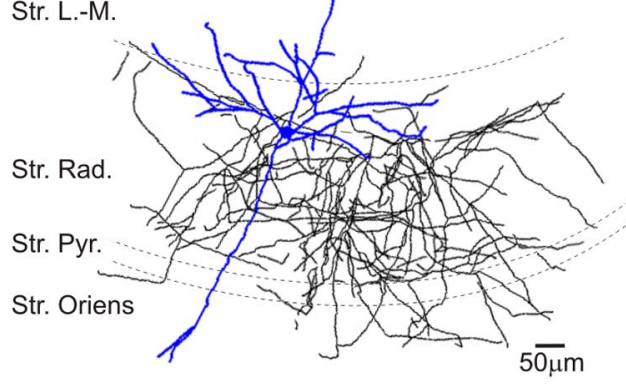

C

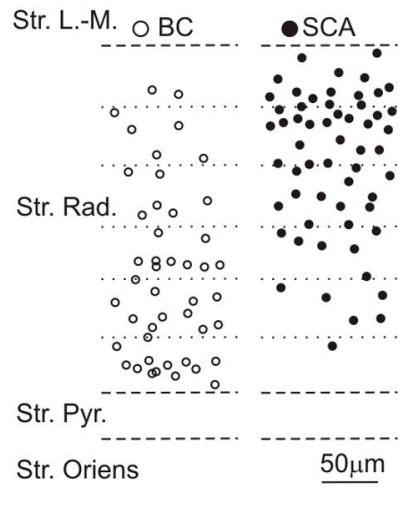

Figure 1. Distinct axonal arborizations of $C C K^{+} B C$ s and SCAs in the $C A 1$ region of the rat hippocampus. $A, B$, Example traces of current-clamp recordings of a $C C{ }^{+} B C$ (in $A$ ) and an $S C A$ (in $B$ ) in response to current steps ( -100 and 80 or $160 \mathrm{pA}$, from resting membrane potential); note the spike frequency adaptation in both cells. Calibration: $50 \mathrm{mV}, 0.2 \mathrm{~s}$. The photomicrographs show the immunopositivity of the cells for CCK but not for PV. The camera lucida drawings of the two cells reveal sharp differences in the axonal layer specificity. C, Schematic diagram indicating the somatic position of the recorded $\mathrm{CCK}^{+} \mathrm{BCS}(n=46)$ and SCA interneurons $(n=58)$ in the stratum radiatum. Str. L.-M., Stratum lacunosum-moleculare; Str. Rad., stratum radiatum; Str. Pyr., stratum pyramidale; Str. Oriens, stratum oriens.

matic and dendritic $\mathrm{CCK}^{+}$terminals. The data show that dendritic $\mathrm{CB}_{1} \mathrm{R}$-expressing GABAergic synapses are under significantly less powerful endocannabinoid-mediated inhibition of GABA release compared with somatic synapses. These results demonstrate an input-specific regulation of neurotransmitter release by hippocampal endocannabinoid signaling.

\section{Materials and Methods}

All protocols were approved by the Institutional Animal Care and Use Committee of the University of California.

Electrophysiology. Transverse hippocampal slices $(350 \mu \mathrm{m})$ were prepared from 17- to 22-d-old Sprague Dawley rats. Slices were incubated in sucrose-containing artificial CSF (ACSF) for an hour ( $85 \mathrm{~mm} \mathrm{NaCl}, 75$ mM sucrose, $2.5 \mathrm{~mm} \mathrm{KCl,} 25 \mathrm{~mm}$ glucose, $1.25 \mathrm{~mm} \mathrm{NaH}_{2} \mathrm{PO}_{4}, 4 \mathrm{~mm}$ $\mathrm{MgCl}_{2}, 0.5 \mathrm{~mm} \mathrm{CaCl}_{2}$, and $24 \mathrm{~mm} \mathrm{NaHCO}_{3}$ ). After the initial incubation period, slices were transferred in the same ACSF solution that was used for recordings ( $126 \mathrm{~mm} \mathrm{NaCl}, 2.5 \mathrm{~mm} \mathrm{KCl}, 26 \mathrm{~mm} \mathrm{NaHCO}_{3}, 2 \mathrm{mM} \mathrm{CaCl}_{2}$, $2 \mathrm{mM} \mathrm{MgCl}_{2}, 1.25 \mathrm{mM} \mathrm{NaH}_{2} \mathrm{PO}_{4}$, and $10 \mathrm{~mm}$ glucose). All electrophysiological recordings were made at $33^{\circ} \mathrm{C}$. Slices were visualized with an upright microscope (Olympus; BX61WI) with infrared-differential interference contrast optics. Whole-cell recordings were obtained from the interneurons with patch pipettes (3-5 $\mathrm{M} \Omega$ ) filled with internal solution containing $126 \mathrm{~mm}$ K-gluconate, $4 \mathrm{~mm} \mathrm{KCl}, 10 \mathrm{~mm}$ HEPES, 4 mм ATP$\mathrm{Mg}, 0.3 \mathrm{~mm}$ GTP-Na, $10 \mathrm{~mm}$ phosphocreatine, and $0.2 \%$ biocytin, $\mathrm{pH}$ $7.2,270-290 \mathrm{mOsm}$. The interneurons were located in layer stratum radiatum. Pyramidal cells (whole-cell voltage-clamp configuration; the holding potential was $-70 \mathrm{mV}$ ) were recorded with internal solution containing $40 \mathrm{~mm} \mathrm{CsCl}, 90 \mathrm{~mm}$ K-gluconate, $1.8 \mathrm{~mm} \mathrm{NaCl}, 1.7 \mathrm{~mm}$ $\mathrm{MgCl}_{2}$, $3.5 \mathrm{~mm} \mathrm{KCl}, 0.05$ mм EGTA, 10 mм HEPES, 2 mм MgATP, 0.4 $\mathrm{mM} \mathrm{Na} \mathrm{N}_{2} \mathrm{GTP}$, and $10 \mathrm{~mm}$ phosphocreatine, $\mathrm{pH}$ 7.2, 270-290 mOsm. All drugs were obtained from Tocris. Recordings were made using MultiClamp700B amplifiers (Molecular Devices). Signals were filtered at $3 \mathrm{kHz}$ using a Bessel filter and digitized at $10 \mathrm{kHz}$ with a Digidata $1440 \mathrm{~A}$ analog-digital interface (Molecular Devices). Series resistances were carefully monitored, and the recordings were discarded if the series resistance changed significantly. The recorded traces were analyzed using the Clampfit 10.2 software (Molecular Devices). Values for average unitary IPSC (uIPSC) amplitudes do not include failures, whereas values for the so-called "effective" uIPSC (euIPSC) (Neu et al., 2007) amplitudes include both successful events and failures. Synchronous IPSCs were individually inspected and included in the analysis based on their onset latency after the presynaptic action potential (for details, see Neu et al., 2007). The uIPSC $10-90 \%$ rise times and decay time constants (the latter assessed within $20 \mathrm{~ms}$ after the peak) were measured from the averaged
uIPSCs in each connected pair, with failures and events with spontaneous events excluded. DSI of uIPSCs was evoked using $500 \mathrm{~ms}$ or $2 \mathrm{~s}$ depolarizing pulses to $0 \mathrm{mV}$, and the IPSCs were compared between the baseline (pre-DSI) period (from -2.0 to $0 \mathrm{~s}$; the latter being the start of the depolarizing pulse) and the DSI period ( 0 to $2.0 \mathrm{~s}$ after the end of the depolarizing pulse) (for details, see Földy et al., 2006). To quantify drug effects, two series of 50 or 100 trials each were averaged immediately before drug application and at the time of maximal effect that occurred 6-10 min after the start of drug application. Data are presented as mean \pm SEM. Paired or unpaired Student's $t$ tests were used for statistical analysis and significant differences were at the level of $p<0.05$.

Immunochemistry and cell identification. After recording, slices were transferred into a fixative solution containing $4 \%$ paraformaldehyde and $0.2 \%$ picric acid in $0.1 \mathrm{~m}$ phosphate buffer. Slices were resectioned into $50-\mu \mathrm{m}$-thin sections and immunoreactivity for CCK was revealed with a mouse monoclonal antibody [mAb 9303; generously provided by the CURE Digestive Diseases Research Center, Antibody RIA Core, Los Angeles, CA (National Institutes of Health Grant DK41301); diluted 1:1000]; immunoreactivity for parvalbumin (PV) was tested with a rabbit polyclonal antibody (PV-28; Swant; diluted 1:1000 in Tris-buffered saline containing $2 \%$ normal goat serum). The reactions were visualized with a goat anti-rabbit IgG conjugated to Alexa 488 (diluted 1:500 in Tris-buffered saline containing $2 \%$ normal goat serum; Invitrogen) and a goat anti-mouse IgG conjugated to Alexa 594 (diluted 1:500), streptavidin conjugated to Alexa 350 for biocytin (diluted 1:500). The sections were then mounted in Vectashield (Vector Laboratories) and analyzed with a fluorescent microscope. To reveal the axonal and dendritic arbors of the interneurons in detail, the biocytin-filled cells were subsequently visualized with 3,3'-diaminobenzidine tetrahydrochloride $(0.015 \%)$ using a standard $\mathrm{ABC}$ kit (Vector). The identification of $\mathrm{CCK}^{+} \mathrm{BCs}$ or SCA interneurons was done based on the distinct axonal morphology (BCs: axons branching in the innermost radiatum and the pyramidale layers; SCAs: axons ramifying predominantly in the stratum radiatum, and to a lesser extent in the oriens) and the immunopositivity to CCK and immunonegativity to PV (Vida et al., 1998; Cope et al., 2002; Pawelzik et al., 2002; Hefft and Jonas, 2005; Földy et al., 2006; Glickfeld and Scanziani, 2006; Ali, 2007; Neu et al., 2007).

\section{Results}

Basic properties of $\mathrm{CCK}^{+}$basket cells and Schaffer collateral-associated cells

Data in this article were obtained using paired whole-cell patchclamp recordings from presynaptic $\mathrm{CCK}^{+}$BCs (Fig. $\left.1 A\right)(46$ pairs) or SCA interneurons (Fig. $1 B$ ) (61 pairs) and postsynaptic 
A

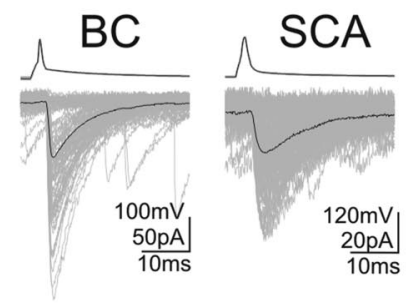

D

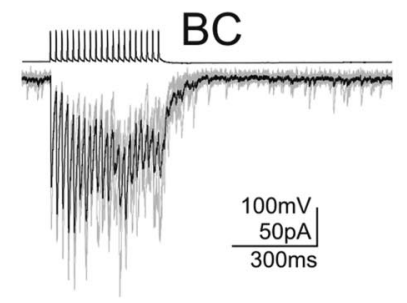

$\mathrm{B}$
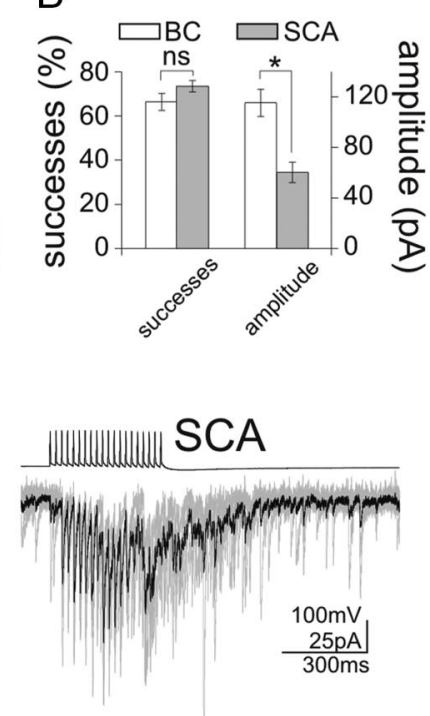

C

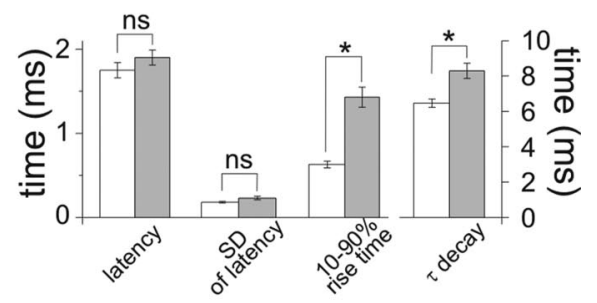

E

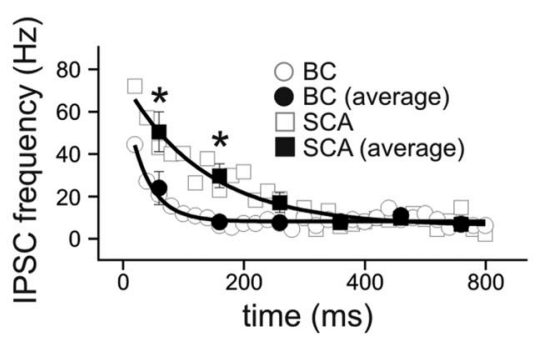

Figure 2. Distinct properties of unitary IPSCs from CCK ${ }^{+}$BCs and SCAs. A, Averaged traces of presynaptic action potentials (top) elicited in a BC and an SCA, and the respective postsynaptic responses (bottom) in pyramidal cells. Note the faster and larger uIPSCs from the CCK ${ }^{+} B C$ compared with the SCA responses. One hundred postsynaptic responses are shown in gray, together with their averages (black). B, Summary data showing the success rates and the uIPSC amplitudes from BCs and SCAs. C, Comparison of synaptic latencies and kinetics of uIPSCs. D, Example traces illustrating the stronger asynchronous IPSCs evoked by firing in an SCA. Five postsynaptic responses (gray) and their averages (black) are shown, in response to a presynaptic train of 20 action potentials at $50 \mathrm{~Hz}$. E, Summary data of the asynchronous events (bin width: 20 or $100 \mathrm{~ms}$, with the latter labeled as "averages" in the figure; the solid lines are single exponential fits to data binned at $20 \mathrm{~ms}$; decay time constant: $\mathrm{BCs}, 35.0 \mathrm{~ms}$; SCAs, $134.4 \mathrm{~ms}$ ). Time 0 is the end of the presynaptic action potential trains. Error bars represent SEM, and the asterisks mark $p<0.05$; ns, not significant.

CA1 pyramidal cells. The recorded BCs and SCAs were all located in the stratum radiatum (Fig. $1 C$ ). The distributions of the location of the recorded cells showed considerable overlap, indicating that it is not possible to unequivocally assign BC versus SCA cell types based on the cell body location alone (note that the apparent differences in cell body locations for the BCs and SCAs shown in Figure $1 C$ should be interpreted with caution, as inadvertent sampling bias by the experimenter may have distorted the true spatial distributions of the cell bodies across the layer). The axons of both the BCs and SCAs originated from the cell body or proximal dendrites, and the dendrites of both cell groups were typically sparsely spiny, occupying predominantly the stratum radiatum, with branches in the lacunosum-moleculare, pyramidale, and oriens (Cope et al., 2002). In agreement with Cope et al. (2002), the average input resistance of SCAs (374.8 $\pm 13.2 \mathrm{M} \Omega$; $n=53)$ was significantly higher than that of the BCs $(201.9 \pm 9.9$ $\mathrm{M} \Omega ; n=39)$, without differences in the resting membrane potential (SCA, $-58.1 \pm 0.8 \mathrm{mV} ; n=53$; BCs, $-58.3 \pm 0.5 \mathrm{mV} ; n=$ 39 ), and both cell types exhibited an accommodating pattern of action potential firing in response to suprathreshold depolarizing current pulses (Fig. 1 A,B) (Földy et al., 2006; Neu at al., 2007).

As may be expected from the somato-dendritic differences in the location of the synaptic inputs, the uIPSCs evoked by BCs were significantly larger and faster than those evoked by SCAs (Fig. 2A-C) (amplitude: BCs, $115.4 \pm 10.8$ pA; SCAs, $60.2 \pm 8.1$ pA; $10-90 \%$ rise time: $B C s, 0.63 \pm 0.04 \mathrm{~ms}$; SCAs, $1.43 \pm 0.12$ ms; decay time constant: BCs, $6.47 \pm 0.24 \mathrm{~ms}$; SCAs, $8.30 \pm 0.44$ ms; BCs, $n=36$; SCAs, $n=50$ ). In contrast, the proportion of presynaptic action potentials that resulted in successful postsynaptic events (i.e., the success rates; BCs, $66.4 \pm 3.9 \%, n=36$; SCAs, $73.4 \pm 2.6 \%, n=50$ ), the synaptic latency (Fig. 2C) (BCs, $1.75 \pm 0.09 \mathrm{~ms}, n=36$; SCAs, $1.90 \pm 0.09 \mathrm{~ms}, n=50$ ) (Fig. $2 C$ ), and the trial-to-trial variability in the latency ("jitter"; SD of the synaptic latency in BCs, $0.18 \pm 0.01 \mathrm{~ms}, n=36$; SCAs, $0.23 \pm$ $0.02 \mathrm{~ms}, n=50$ ) were also not different between the two cell types
(Fig. 2B,C). Finally, as asynchronous GABA release has been shown to occur frequently in $\mathrm{CCK}^{+}$hippocampal interneurons (Hefft and Jonas, 2005; Daw et al., 2009), we also examined asynchronous uIPSCs after a train of action potentials (20 action potentials at $50 \mathrm{~Hz}$ ) in BCs and SCAs. In agreement with results from a recent study (Daw et al., 2009), both BCs and SCAs showed asynchronous release, with the SCAs displaying stronger asynchronous release compared with BCs (Fig. 2D,E) (BCs, $n=$ 11; SCAs, $n=9$ ).

Together, these results demonstrate significant differences in both the intrinsic and baseline synaptic properties of BCs and SCAs, confirming that these $\mathrm{CCK}^{+}$interneurons, identified on the basis of their axonal projections, form two distinct classes of GABAergic neurons within the CA1 region of the hippocampus.

\section{Smaller DSI at SCA to pyramidal cell synapses}

Next, we examined endocannabinoid signaling at BC and SCA synapses on CA1 pyramidal cells. First, we compared DSI (Llano et al., 1991; Pitler and Alger, 1992; Kreitzer and Regehr, 2001; Ohno-Shosaku et al., 2001; Wilson and Nicoll, 2001), a postsynaptic activity-dependent, short-term presynaptic plasticity mechanism characteristic of most synapses formed by $\mathrm{CB}_{1} \mathrm{R}$ expressing presynaptic GABAergic neurons. In the case of $\mathrm{BC}$ to CA1 pyramidal cell pairs, as reported previously (Földy et al., 2006; Glickfeld and Scanziani, 2006), 500-ms-long depolarization of the postsynaptic cell to $0 \mathrm{mV}$ evoked strong DSI (Fig. $3 \mathrm{~A}$ ) (DSI, $29.1 \pm 6.3 \%$ of baseline euIPSC amplitudes; $n=15$ ) that recovered to the control level (recovery, $100.9 \pm 5.7 \%$ of control euIPSC amplitude). In contrast, the same postsynaptic depolarizing pulses caused significantly smaller DSI in SCA to pyramidal cell pairs (Fig. 3A) (DSI, 78.4 $\pm 6.7 \%$ of baseline euIPSC amplitudes; recovery, $100.5 \pm 6.8 \% ; n=16)$. In fact, even prolonged (2-s-long) depolarization of the postsynaptic cell to $0 \mathrm{mV}$ did not produce larger DSI at SCA to pyramidal cell synapses (DSI after 2 s depolarizing step, $79.6 \pm 16.1 \%$ of baseline euIPSC ampli- 
tude; $n=5$ ). These results indicate that, in addition to intrinsic and basic synaptic properties, BCs and SCAs also display significant differences in cannabinoid synaptic signaling at their output synapses.

\section{Lack of tonic $\mathrm{CB}_{1} \mathrm{R}$-mediated inhibition of GABA release at $\mathrm{SCA}$ synapses}

The findings described in the previous paragraph indicating smaller DSI in SCAs were unexpected, because, first, the endocannabinoid responsible for DSI is 2-AG (Hashimotodani et al., 2007; Pan et al., 2009; Gao et al., 2010; Tanimura et al., 2010) and several key enzymes involved in 2-AG synthesis have been shown to be preferentially expressed in CA1 pyramidal cell dendrites (Katona et al., 2006; Yoshida et al., 2006), and, second, the density of $\mathrm{CB}_{1}$ Rs was reported to be similar on BC and SCA terminals (Nyiri et al., 2005). However, it cannot be excluded that the somatic depolarizing pulses used to evoke DSI may not provide an efficient local stimulus (rise in intradendritic $\mathrm{Ca}^{2+}$ ) (Rancz and Häusser, 2006) for DSI at dendritic synapses formed by SCAs. Therefore, another form of endocannabinoid signaling was also examined, namely, the $\mathrm{CB}_{1}$ receptor-mediated tonic inhibition of GABA release (Losonczy et al., 2004; Neu et al., 2007) that can be studied without the need for externally imposed depolarization of pyramidal cells.

At BC synapses, as reported previously (Neu et al., 2007), bath application of the $\mathrm{CB}_{1} \mathrm{R}$ antagonist (and inverse agonist) $N$-(piperidin-1-yl)-5-(4-iodophenyl)-1(2,4-dichlorophenyl)-4-methyl-1 H-pyrazole-3-carboxamide (AM251) (10 $\mu \mathrm{M})$ significantly increased the proportion of presynaptic action potentials resulting in postsynaptic events (Fig. 3B) (percentage successful transmission: predrug control, $46.3 \pm 12.7 \%$; AM251, $79.5 \pm 6.1 \%$; $n=$ 5 ) and the euIPSC amplitudes (Fig. $3 B)(51.6 \pm 23.7$ to $80.3 \pm$ $24.6 \mathrm{pA} ; n=5)$. In contrast to BCs, application of AM251 at the same concentration did not increase the proportion of successful transmission at SCA synapses (Fig. 3B) (successes: control: predrug control, $55.4 \pm 6.6 \%$; AM251, $57.6 \pm 7.6 \% ; n=7)$, and it also failed to increase the euIPSC amplitudes (Fig. 3B) (13.6 \pm 3.3 to $14.8 \pm 4.5 \mathrm{pA} ;=7$ ). These results, showing the absence of $\mathrm{CB}_{1} \mathrm{R}$-dependent tonic inhibition of GABA release at the SCA to pyramidal cell synapses, are in general agreement with the significantly smaller DSI at SCA inputs.

Smaller metabotropic glutamate receptor activation-induced, $\mathrm{CB}_{1} \mathrm{R}$-dependent depression of GABA release at SCA synapses In addition to DSI and tonic inhibition of GABA release investigated above, a third form of endocannabinoid-mediated regulation of GABA release is linked to the activation of $\mathrm{G}_{\mathrm{q} / 11}$-linked metabotropic receptors, which results in the synthesis of endocannabinoids through PLC (phospholipase C) and DGL $\alpha$ (Galante and Diana, 2004; Haj-Dahmane and Shen, 2005;
Hashimotodani et al., 2005). Therefore, in the next series of experiments, we examined whether the type $1 \mathrm{mGluR}$ agonist $(S)$ 3,5-dihydroxyphenylglycine (DHPG) inhibits GABA release (Maejima et al., 2001; Varma et al., 2001) differentially in $\mathrm{CCK}^{+}$ BCs (Neu et al., 2007) and SCAs. Application of DHPG at a relatively high concentration $(25 \mu \mathrm{M})$ resulted in a strong suppression of euIPSCs (Fig. 4A) (euIPSC amplitude in DHPG, with respect to predrug control: $\mathrm{BC}, 3.6 \pm 2.1 \%, n=3$; SCAs, $1.6 \pm$ $1.1 \%, n=3$ ) that was fully reversible after washout. These results show that $\mathrm{G}_{\mathrm{q} / 11}$ activation can powerfully control GABA release from both somatic and dendritic $\mathrm{CB}_{1} \mathrm{R}$-expressing axon terminals. However, low concentration of DHPG $(1 \mu \mathrm{M})$ revealed significant differences between the two interneuronal groups; $1 \mu \mathrm{M}$ DHPG caused strong depression of euIPSCs at BC synapses, but failed to result in any changes in transmission at SCA inputs (Fig. $4 A$ ) (amplitude of euIPSC in $1 \mu \mathrm{M}$ DHPG, with respect to control: BC, $15.2 \pm 6.6 \%, n=5$; SCAs, $100.8 \pm 14.0 \%, n=7$ ). Therefore, in agreement with the DSI and the tonic inhibition results, the DHPG data also indicated less potent cannabinoid control of GABA release from dendritic compared with somatic terminals. 
A
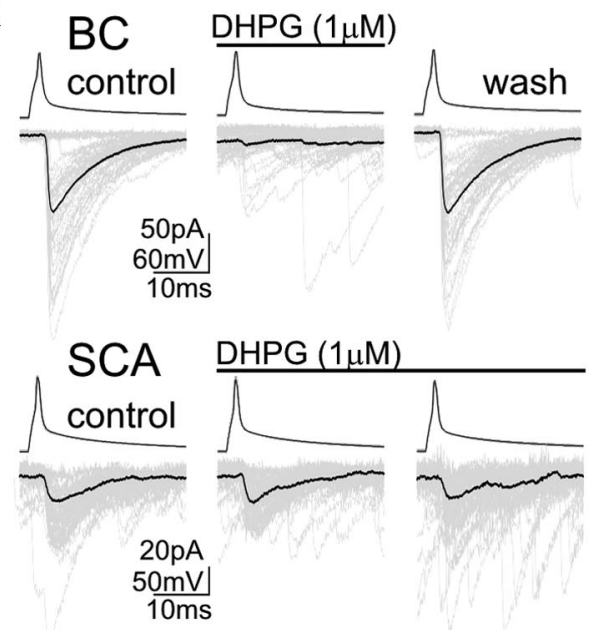

B SCA

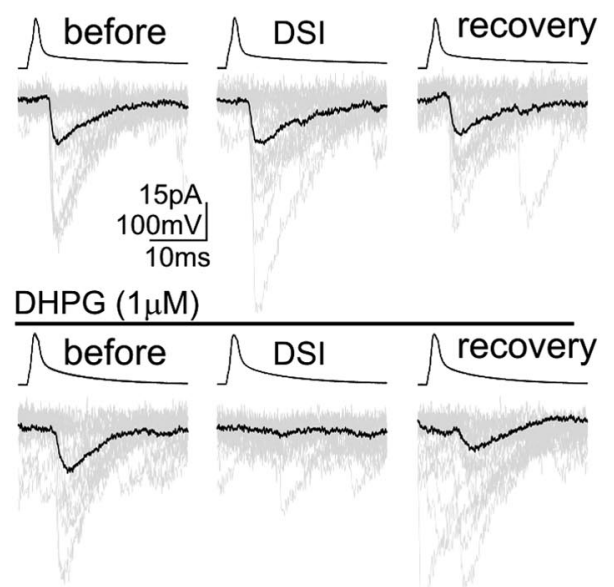

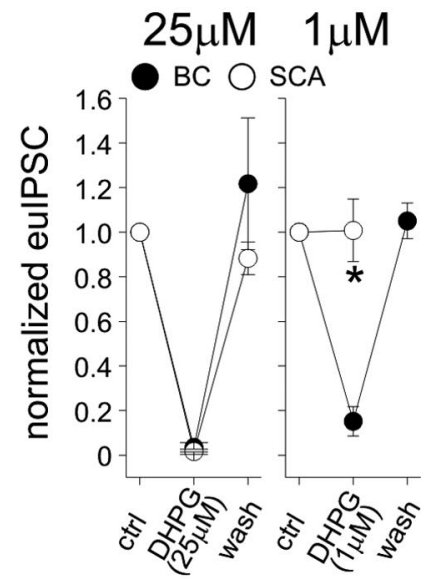

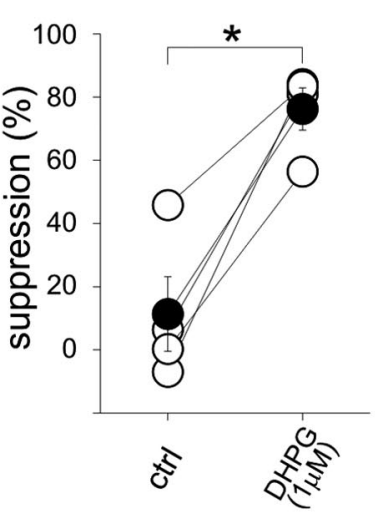

Figure 4. Weaker mGluR-mediated inhibition of GABA release from dendritic versus perisomatic $C B_{1} R$-expressing terminals, and the synergistic effects of postsynaptic depolarization and metabotropic receptor activation on SCA inputs. $A$, Bath application of the mGluR agonist DHPG $(1 \mu \mathrm{M})$ abolished the transmission from a BC but not from an SCA. Fifty consecutive control eulPSCs ("control"; gray) and their averages (black) are shown, in response to single action potentials $(10 \mathrm{~Hz})$ in the presynaptic interneuron. Summary data of high and low DHPG concentrations are shown; note that the higher concentration of DHPG was able to abolish both the $B C$ and the SCA responses. $\boldsymbol{B}$, DHPG strongly enhances DSI at the SCA to pyramidal cell synapse. Example recordings are shown on the left; note that, without DHPG, the presynaptic SCA showed no DSI (top), but powerful DSI could be observed in the same pair in the presence of DHPG. Summary data are presented on the right. Error bars represent SEM, and the asterisks mark $p<0.05$.

Previous studies demonstrated that activation of $\mathrm{G}_{\mathrm{q} / 11}$ G-protein-coupled receptors can enhance DSI at BC synapses (Kim et al., 2002; Ohno-Shosaku et al., 2002; Edwards et al., 2008). Thus, we examined whether such synergistic effects are also present at SCA to pyramidal cell dendrite synapses. In control ACSF, postsynaptic depolarization (500 ms to $0 \mathrm{mV}$ ) caused only weak DSI at SCA inputs (Fig. 4B) (amplitude of euIPSCs during DSI in ACSF, with respect to pre-DSI baseline: $88.6 \pm 11.8 \% ; n=4$ ), in agreement with the results described above. However, in the presence of $1 \mu \mathrm{M}$ DHPG, postsynaptic depolarizing pulses caused significantly more robust DSI in these pairs (Fig. $4 B$ ) (amplitude of euIPSCs during DSI in DHPG, with respect to pre-DSI baseline: $23.8 \pm 6.8 \% ; n=4$ ). These data show that the intracellular $\mathrm{Ca}^{2+}$ rise-driven (DSI) and the $G_{q / 11}$-dependent endocannabinoid synthetic pathways can act synergistically at SCA synapses.

\section{Differential sensitivity of $\mathrm{BC}$ and SCA synapses to exogenously applied $\mathrm{CB}_{1} \mathrm{R}$ agonist}

Together, the data above pointed to a weaker $\mathrm{CB}_{1} \mathrm{R}$-dependent control of GABA release at SCA synapses. It is not currently possible to

measure endocannabinoid release directly at postsynaptic dendritic versus somatic synapses to assess potential postsynaptic differences underlying the less efficacious endocannabinoid-mediated regulation of GABA release from SCA terminals. However, presynaptic differences may exist between BC and SCA terminals that could contribute to, or perhaps even cause, the less powerful control of GABA release by endocannabinoids at SCA synapses. Therefore, in the final series of paired recording experiments, we examined whether BC and SCA synapses exhibit differential sensitivity to the exogenously applied $\mathrm{CB}_{1} \mathrm{R}$ agonist $R$-(+)-(2,3-dihydro-5-methyl-3-[(4-morpholinyl)methyl]pyrol[1,2,3-de]-1,4-benzoxazin-6-yl)(1-naphthalenyl)methanone monomethanesulfonate [WIN55,212-2 (WIN)]. First, we tested the effects of relatively high concentration of WIN $(5 \mu \mathrm{M})$ on the pairs. WIN strongly attenuated euIPSC amplitudes at both the BC and SCA synapses and the effects did not differ between two groups (Fig. 5) (BC, amplitude of euIPSCs in WIN, with respect to predrug control, $28.6 \pm 13.9 \%, n=8$; SCA, $10.4 \pm 3.3 \%, n=4)$. The WIN-mediated inhibition of euIPSC amplitudes was fully reversible by the $\mathrm{CB}_{1} \mathrm{R}$ antagonist $\mathrm{AM} 251$ $(10 \mu \mathrm{M})$ (BC, amplitude of euIPSCs in AM251, with respect to predrug control, $130.7 \pm 9.4 \%, n=5$; SCA, $105.6 \pm 35.7 \%$, $n=4)$. However, significant differences were revealed by a low concentration (100 nM) of WIN between the two groups. Specifically, WIN at $100 \mathrm{~nm}$ caused strong suppression of euIPSC amplitudes at BC synapses (Fig. 5A,B) (amplitude of euIPSCs in WIN, with respect to predrug control, $20.3 \pm 6.4 \% ; n=6$ ) that was fully reversible after application of AM251 (10 $\mu \mathrm{M})$ (pre-WIN control, $-72.8 \pm 10.7 \mathrm{pA}$; WIN, $-13.7 \pm 3.7 \mathrm{pA}$; AM251, $-107.5 \pm$ $15.6 \mathrm{pA} ; n=6)$. In contrast, the same low concentration of WIN produced significantly smaller changes in euIPSC amplitudes at SCA to pyramidal cell synapses (Fig. $5 A, B$ ) (euIPSC amplitude in WIN, with respect to predrug control, $70.8 \pm 6.4 \% ; n=4$ ), with the WIN-induced decreases in SCA evoked euIPSCs also being fully reversible by the application of the $\mathrm{CB}_{1}$ receptor antagonist AM251 (pre-WIN control, $-63.7 \pm 28.4 \mathrm{pA}$; WIN, $-48.2 \pm 23.5$ pA; AM251, $-61.7 \pm 27.7 \mathrm{pA} ; n=4$ ). These data show that presynaptic differences exist between the $\mathrm{CB}_{1} \mathrm{R}$-dependent control of somatic versus dendritic GABAergic synapses on CA1 pyramidal cells.

\section{Discussion}

The key findings of the present paper are the following: (1) Single presynaptic action potentials in SCAs generate smaller and slower postsynaptic events compared with BCs, without differences in the probability of successful transmission or in the synaptic latency; (2) inputs originating from SCAs exhibit smaller DSI; (3) dendritic synapses show no $\mathrm{CB}_{1} \mathrm{R}$-dependent, tonic in- 
hibition of GABA release; (4) SCA synapses display significantly weaker mGluR activation-dependent endocannabinoid regulation of GABA release; (5) similarly to $\mathrm{BC}$ inputs, the cannabinoid pathways regulating the SCA to pyramidal cell synapses can act synergistically; and (6) the sensitivity of SCA to pyramidal cell synapses to cannabinoid ligands is significantly smaller compared with BC to pyramidal cell synapses. Together, these paired recording data demonstrate, for the first time, that prominent, systematic differences exist between the endocannabinoid-mediated control of somatic and dendritic GABA release in the hippocampus.

\section{Differential modulation of somatic and dendritic hippocampal GABAergic synapses by endocannabinoids}

The synaptic release of GABA is tightly controlled both in space and time in hippocampal circuits. Of the currently recognized $\sim 21$ types of GABAergic cells in the CA1 (Klausberger and Somogyi, 2008), CCK-expressing interneurons are known to provide innervation to both the perisomatic and dendritic regions of pyramidal cells (Klausberger, 2009). Although on immunostained sections the CA1 somatic layer and the innermost part of the radiatum closest to the stratum pyramidale appear to exhibit the densest fiber staining for CCK, the dendritic layers also show significant numbers of immunoreactive axons. Although endocannabinoid signaling has been extensively examined at perisomatic CCK- and $\mathrm{CB}_{1} \mathrm{R}$-expressing synapses originating from $\mathrm{BCs}$, there has not been a systematic study specifically designed to determine properties of $\mathrm{CB}_{1} \mathrm{R}$-mediated control of GABA release at dendritic synapses in the hippocampus.

The dendritic $\mathrm{CCK}^{+}$GABAergic inputs in the radiatum and oriens layers in the $\mathrm{CA} 1$ area have been shown to predominantly arise from the SCAs (Cope et al., 2002), a cell type that is homologous to the also CCK-positive double bouquet cells in the neocortex (Freund et al., 1986; DeFelipe et al., 1989). Schaffer collateral-associated cells, so named because their axonal field conspicuously coregisters with the Schaffer collateral inputs from the CA3 pyramidal cells to the CA1 radiatum and oriens layers, appear to be strategically placed to modulate the excitatory input from the CA3. Glutamatergic synaptic excitation is a major mechanism for engaging the endocannabinoid synthetic pathways, either in the form of postsynaptic depolarization-induced intracellular $\mathrm{Ca}^{2+}$ rise or through the activation of postsynaptic mGluRs and downstream second messenger systems (Kano et al., 2009). Our results show that endocannabinoid control of dendritic GABAergic inputs is less powerful than that of the somatic inputs, a finding that was constant regardless of whether we examined DSI, tonic inhibition of GABA release by $\mathrm{CB}_{1} \mathrm{Rs}$, or mGluR-driven endocannabinoid-mediated inhibition of GABA release. As 2-AG is the retrograde lipid messenger that causes depression of GABA release after postsynaptic depolarization (Hashimotodani et al., 2007; Pan et al., 2009; Gao et al., 2010; Tanimura et al., 2010), and the synthesizing molecular pathways for 2-AG are localized in dendritic spines (Katona et al., 2006; Yoshida et al., 2006), it was unexpected to
B

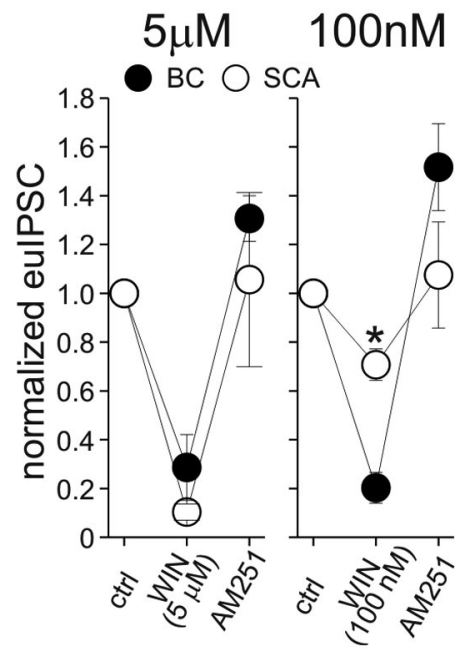

find that SCA inputs showed significantly less DSI than BC inputs, especially since quantitative immunocytochemical studies at the electron microscope level demonstrated that the density of $\mathrm{CB}_{1} \mathrm{Rs}$ is similar on BC and SCA terminals (Nyiri et al., 2005). However, our finding of small DSI from SCAs compared with BCs is in agreement with a previous study that used dendritic recordings from CA1 pyramidal cells to show that the DSI of extracellular stimulationinduced dendritic IPSCs was smaller than DSI of somatic inputs (Morishita and Alger, 2001). Given the similar density of $\mathrm{CB}_{1} \mathrm{Rs}$ at somatic and dendritic GABAergic terminals (Nyiri et al., 2005), our results demonstrating differential WIN sensitivity of SCA and BC terminals suggest the presence of presynaptic functional differences downstream from $C_{1} R$ s (e.g., involving $C_{1} R$ coupling to G-proteins and/or $\mathrm{Ca}^{2+}$ channels). It is interesting to note here that $\mathrm{CB}_{1} \mathrm{Rs}$ are also present on some hippocampal glutamatergic axons, and, despite their lower expression levels of $\mathrm{CB}_{1} \mathrm{Rs}$ compared with $\mathrm{CCK}^{+} \mathrm{BCs}$ (Katona et al., 2006), $\mathrm{CB}_{1}$ Rs on glutamatergic terminals have been shown to play powerful regulatory roles in hippocampal excitability (Marsicano et al., 2003; Monory et al., 2006). Therefore, it seems that the relative densities of $\mathrm{CB}_{1}$ Rs on GABAergic and glutamatergic axon terminals by themselves are not fully reliable indicators of their respective strengths in regulating transmitter release by endocannabinoids. It should be noted that high concentrations of DHPG and WIN achieved near-complete inhibition of GABA release from both $B C$ and SCA terminals, indicating that $\mathrm{CB}_{1} \mathrm{Rs}$ at dendritic GABAergic synapses are also capable of effectively blocking neurotransmitter release. In addition, although our data point to presynaptic factors underlying the observed differential cannabinoid regulation of SCA versus $\mathrm{BC}$ inputs, it is possible that additional mechanisms may also contribute to the input-specific difference. In particular, differential release of endocannabinoids may take place along the somato-dendritic axis, and location-dependent endocannabinoid degradation/uptake processes may also play additional roles.

Although the main focus of this paper has been the differential regulation of GABA release by endocannabinoids from dendritic 
and perisomatic $\mathrm{CB}_{1} \mathrm{R}$-expressing terminals, it is interesting to note that the spatially segregated GABAergic inputs in turn may also differentially affect endocannabinoid synthesis and release. Indeed, synaptically evoked local dendritic $\mathrm{Ca}^{2+}$ spikes can be efficient triggers of endocannabinoid-mediated retrograde inhibition of transmitter release (Rancz and Häusser, 2006; Regehr et al., 2009), and it has been shown that dendritic GABAergic inputs can powerfully inhibit $\mathrm{Ca}^{2+}$ spikes, whereas perisomatic inputs typically are more capable to regulate $\mathrm{Na}^{+}$spike generation (Miles et al., 1996). The relatively small and slow SCA-elicited euIPSCs (Fig. 2) are almost certainly more powerful locally at their input sites in the dendrites, which, together with their propensity for asynchronous GABA release, may enable these dendritically projecting interneurons to significantly modulate local dendritic $\mathrm{Ca}^{2+}$ signals in CA1 pyramidal cells.

\section{Functional implications and outlook}

$\mathrm{CCK}^{+}$hippocampal interneurons likely play several distinct, functionally important roles in the hippocampus. For example, $\mathrm{CCK}^{+}$interneurons in CA1 receive specific inputs from brainstem modulatory nuclei (for review, see Freund, 2003), and they may be particularly suited for the integration of excitation from multiple afferents (Glickfeld and Scanziani, 2006). In addition, $\mathrm{CCK}^{+}$interneurons fire at different times from $\mathrm{PV}^{+} \mathrm{BC}$ during in vivo theta, gamma, and ripple oscillations (Klausberger et al., 2005), and their firing is also temporally separated from CA1 pyramidal discharges. However, the available in vivo data so far have not yet revealed sharp differences between $\mathrm{CCK}^{+} \mathrm{BCs}$ and SCAs, in contrast to $\mathrm{PV}^{+}$basket cells and dendritically projecting bistratified cells (Klausberger et al., 2004). In general, in vivo recorded $\mathrm{CCK}^{+}$interneurons fire significantly earlier during the gamma cycle compared with other interneurons, and, based on the timing of their discharges, it has been suggested that $\mathrm{CCK}^{+}$ interneurons may play a role in setting the firing threshold of pyramidal cells (Klausberger, 2009). $\mathrm{CCK}^{+}$interneurons fire during theta oscillations at the time when phase-precessing pyramidal cells start firing (O'Keefe and Recce, 1993), suggesting the potential functional importance of $\mathrm{CB}_{1} \mathrm{R}$-dependent inhibition of GABAergic inputs specifically to those place cells that are active (Klausberger et al., 2005). Although the powerful, complex spike bursts emitted by a pyramidal cell when a rat enters the place field of that given place cell (Harris et al., 2001) are likely to enhance endocannabinoid synthesis specifically in that cell, it is not yet fully understood what roles, if any, retrograde endocannabinoid signaling may play in the implementation of sparse coding in cell assemblies (Robbe et al., 2006).

Interestingly, on average, $\mathrm{CCK}^{+}$cells [with some exceptions (Klausberger et al., 2005; Jinno et al., 2007)] do not change their firing rates during ripple oscillations. The latter finding is especially surprising, since ripples are generated by strong excitatory input from CA3 pyramidal cells (Csicsvari et al., 2000), and BCs and SCAs have dendrites in the radiatum and oriens layers, and therefore are likely to receive direct Schaffer collateral inputs. In addition, unlike other interneuronal subtypes, $\mathrm{CCK}^{+}$cells in vivo appeared to exhibit a highly ripple episode-dependent behavior, where the same cell sometimes was excited and sometimes inhibited during single ripple episodes (Klausberger et al., 2005). The latter observations indicate that $\mathrm{CCK}^{+}$cells may be especially sensitive to the recent activity history of the hippocampal network. The investigations of these functional issues will be important in the future, together with efforts aimed at understanding how the molecular diversity of $\mathrm{CCK}^{+}$interneurons (for example, the mutually exclusive expression of vasoactive intestinal polypeptide or vesicular glutamate transporter type 3 in $\mathrm{CCK}^{+}$ cells) (Somogyi et al., 2004) may segregate with distinct physiological properties.

\section{References}

Ali AB (2007) Presynaptic inhibition of $\mathrm{GABA}_{\mathrm{A}}$ receptor-mediated unitary IPSPs by cannabinoid receptors at synapses between CCK-positive interneurons in rat hippocampus. J Neurophysiol 98:861-869.

Cope DW, Maccaferri G, Márton LF, Roberts JD, Cobden PM, Somogyi P (2002) Cholecystokinin-immunopositive basket and Schaffer collateralassociated interneurones target different domains of pyramidal cells in the CA1 area of the rat hippocampus. Neuroscience 109:63-80.

Cossart R, Esclapez M, Hirsch JC, Bernard C, Ben-Ari Y (1998) GluR5 kainate receptor activation in interneurons increases tonic inhibition of pyramidal cells. Nat Neurosci 1:470-478.

Csicsvari J, Hirase H, Mamiya A, Buzsáki G (2000) Ensemble patterns of hippocampal CA3-CA1 neurons during sharp wave-associated population events. Neuron 28:585-594.

Daw MI, Tricoire L, Erdelyi F, Szabo G, McBain CJ (2009) Asynchronous transmitter release from cholecystokinin-containing inhibitory interneurons is widespread and target-cell independent. J Neurosci 29:11112-11122.

DeFelipe J, Hendry SH, Jones EG (1989) Synapses of double bouquet cells in monkey cerebral cortex visualized by calbindin immunoreactivity. Brain Res 503:49-54.

Edwards DA, Zhang L, Alger BE (2008) Metaplastic control of the endocannabinoid system at inhibitory synapses in hippocampus. Proc Natl Acad Sci U S A 105:8142-8147.

Elfant D, Pál BZ, Emptage N, Capogna M (2008) Specific inhibitory synapses shift the balance from feedforward to feedback inhibition of hippocampal CA1 pyramidal cells. Eur J Neurosci 27:104-113.

Földy C, Neu A, Jones MV, Soltesz I (2006) Presynaptic, activity-dependent modulation of cannabinoid type 1 receptor-mediated inhibition of GABA release. J Neurosci 26:1465-1469.

Freund TF (2003) Interneuron diversity series: rhythm and mood in perisomatic inhibition. Trends Neurosci 26:489-495.

Freund TF, Maglóczky Z, Soltész I, Somogyi P (1986) Synaptic connections, axonal and dendritic patterns of neurons immunoreactive for cholecystokinin in the visual cortex of the cat. Neuroscience 19:1133-1159.

Galante M, Diana MA (2004) Group I metabotropic glutamate receptors inhibit GABA release at interneuron-Purkinje cell synapses through endocannabinoid production. J Neurosci 24:4865-4874.

Gao Y, Vasilyev DV, Goncalves MB, Howell FV, Hobbs C, Reisenberg M, Shen R, Zhang MY, Strassle BW, Lu P, Mark L, Piesla MJ, Deng K, Kouranova EV, Ring RH, Whiteside GT, Bates B, Walsh FS, Williams G, Pangalos MN, et al. (2010) Loss of retrograde endocannabinoid signaling and reduced adult neurogenesis in diacylglycerol lipase knock-out mice. J Neurosci 30:2017-2024.

Glickfeld LL, Scanziani M (2006) Distinct timing in the activity of cannabinoid-sensitive and cannabinoid-insensitive basket cells. Nat Neurosci 9:807-815.

Haj-Dahmane S, Shen RY (2005) The wake-promoting peptide orexin-B inhibits glutamatergic transmission to dorsal raphe nucleus serotonin neurons through retrograde endocannabinoid signaling. J Neurosci 25:896-905.

Hájos N, Mody I (1997) Synaptic communication among hippocampal interneurons: properties of spontaneous IPSCs in morphologically identified cells. J Neurosci 17:8427-8442.

Harris KD, Hirase H, Leinekugel X, Henze DA, Buzsáki G (2001) Temporal interaction between single spikes and complex spike bursts in hippocampal pyramidal cells. Neuron 32:141-149.

Hashimotodani Y, Ohno-Shosaku T, Tsubokawa H, Ogata H, Emoto K, Maejima T, Araishi K, Shin HS, Kano M (2005) Phospholipase Cbeta serves as a coincidence detector through its $\mathrm{Ca}^{2+}$ dependency for triggering retrograde endocannabinoid signal. Neuron 45:257-268.

Hashimotodani Y, Ohno-Shosaku T, Kano M (2007) Presynaptic monoacylglycerol lipase activity determines basal endocannabinoid tone and terminates retrograde endocannabinoid signaling in the hippocampus. J Neurosci 27:1211-1219.

Hefft S, Jonas P (2005) Asynchronous GABA release generates long-lasting inhibition at a hippocampal interneuron-principal neuron synapse. Nat Neurosci 8:1319-1328. 
Heifets BD, Castillo PE (2009) Endocannabinoid signaling and long-term synaptic plasticity. Annu Rev Physiol 71:283-306.

Jinno S, Klausberger T, Marton LF, Dalezios Y, Roberts JD, Fuentealba P, Bushong EA, Henze D, Buzsáki G, Somogyi P (2007) Neuronal diversity in GABAergic long-range projections from the hippocampus. J Neurosci 27:8790-8804.

Kano M, Ohno-Shosaku T, Hashimotodani Y, Uchigashima M, Watanabe M (2009) Endocannabinoid-mediated control of synaptic transmission. Physiol Rev 89:309-380.

Katona I, Urbán GM, Wallace M, Ledent C, Jung KM, Piomelli D, Mackie K, Freund TF (2006) Molecular composition of the endocannabinoid system at glutamatergic synapses. J Neurosci 26:5628-5637.

Kim J, Isokawa M, Ledent C, Alger BE (2002) Activation of muscarinic acetylcholine receptors enhances the release of endogenous cannabinoids in the hippocampus. J Neurosci 22:10182-10191.

Klausberger T (2009) GABAergic interneurons targeting dendrites of pyramidal cells in the CA1 area of the hippocampus. Eur J Neurosci 30:947-957.

Klausberger T, Somogyi P (2008) Neuronal diversity and temporal dynamics: the unity of hippocampal circuit operations. Science 321:53-57.

Klausberger T, Márton LF, Baude A, Roberts JD, Magill PJ, Somogyi P (2004) Spike timing of dendrite-targeting bistratified cells during hippocampal network oscillations in vivo. Nat Neurosci 7:41-47.

Klausberger T, Marton LF, O'Neill J, Huck JH, Dalezios Y, Fuentealba P, Suen WY, Papp E, Kaneko T, Watanabe M, Csicsvari J, Somogyi P (2005) Complementary roles of cholecystokinin- and parvalbumin-expressing GABAergic neurons in hippocampal network oscillations. J Neurosci 25:9782-9793.

Kreitzer AC, Regehr WG (2001) Cerebellar depolarization-induced suppression of inhibition is mediated by endogenous cannabinoids. J Neurosci 21:RC174(1-5).

Llano I, Leresche N, Marty A (1991) Calcium entry increases the sensitivity of cerebellar Purkinje cells to applied GABA and decreases inhibitory synaptic currents. Neuron 6:565-574.

Losonczy A, Biro AA, Nusser Z (2004) Persistently active cannabinoid receptors mute a subpopulation of hippocampal interneurons. Proc Natl Acad Sci U S A 101:1362-1367.

Lujan R, Nusser Z, Roberts JD, Shigemoto R, Somogyi P (1996) Perisynaptic location of metabotropic glutamate receptors mGluR1 and mGluR5 on dendrites and dendritic spines in the rat hippocampus. Eur J Neurosci 8:1488-1500.

Maejima T, Hashimoto K, Yoshida T, Aiba A, Kano M (2001) Presynaptic inhibition caused by retrograde signal from metabotropic glutamate to cannabinoid receptors. Neuron 31:463-475.

Marsicano G, Lutz B (1999) Expression of the cannabinoid receptor CB1 in distinct neuronal subpopulations in the adult mouse forebrain. Eur J Neurosci 11:4213-4225.

Marsicano G, Goodenough S, Monory K, Hermann H, Eder M, Cannich A, Azad SC, Cascio MG, Gutiérrez SO, van der Stelt M, López-Rodriguez ML, Casanova E, Schütz G, Zieglgänsberger W, Di Marzo V, Behl C, Lutz B (2003) CB1 cannabinoid receptors and on-demand defense against excitotoxicity. Science 302:84-88.

Miles R, Tóth K, Gulyás AI, Hájos N, Freund TF (1996) Differences between somatic and dendritic inhibition in the hippocampus. Neuron 16:815823.

Monory K, Massa F, Egertová M, Eder M, Blaudzun H, Westenbroek R, Kelsch W, Jacob W, Marsch R, Ekker M, Long J, Rubenstein JL, Goebbels S, Nave KA, During M, Klugmann M, Wölfel B, Dodt HU, Zieglgänsberger W, Wotjak CT, et al. (2006) The endocannabinoid system controls key epileptogenic circuits in the hippocampus. Neuron 51:455-466.

Morishita W, Alger BE (2001) Direct depolarization and antidromic action potentials transiently suppress dendritic IPSPs in hippocampal CA1 pyramidal cells. J Neurophysiol 85:480-484.
Neu A, Földy C, Soltesz I (2007) Postsynaptic origin of CB1-dependent tonic inhibition of GABA release at cholecystokinin-positive basket cell to pyramidal cell synapses in the CA1 region of the rat hippocampus. J Physiol 578:233-247.

Nyíri G, Cserép C, Szabadits E, Mackie K, Freund TF (2005) CB1 cannabinoid receptors are enriched in the perisynaptic annulus and on preterminal segments of hippocampal GABAergic axons. Neuroscience 136:811822 .

Ohno-Shosaku T, Maejima T, Kano M (2001) Endogenous cannabinoids mediate retrograde signals from depolarized postsynaptic neurons to presynaptic terminals. Neuron 29:729-738.

Ohno-Shosaku T, Shosaku J, Tsubokawa H, Kano M (2002) Cooperative endocannabinoid production by neuronal depolarization and group I metabotropic glutamate receptor activation. Eur J Neurosci 15:953-961.

O’Keefe J, Recce ML (1993) Phase relationship between hippocampal place units and the EEG theta rhythm. Hippocampus 3:317-330.

Pan B, Wang W, Long JZ, Sun D, Hillard CJ, Cravatt BF, Liu QS (2009) Blockade of 2-arachidonoylglycerol hydrolysis by selective monoacylglycerol lipase inhibitor 4-nitrophenyl 4-(dibenzo[d][1,3]dioxol-5-yl(hydroxy)methyl) piperidine-1-carboxylate (JZL184) enhances retrograde endocannabinoid signaling. J Pharmacol Exp Ther 331:591-597.

Pawelzik H, Hughes DI, Thomson AM (2002) Physiological and morphological diversity of immunocytochemically defined parvalbumin- and cholecystokinin-positive interneurones in CA1 of the adult rat hippocampus. J Comp Neurol 443:346-367.

Pitler TA, Alger BE (1992) Postsynaptic spike firing reduces synaptic $\mathrm{GABA}_{\mathrm{A}}$ responses in hippocampal pyramidal cells. J Neurosci 12:41224132.

Rancz EA, Häusser M (2006) Dendritic calcium spikes are tunable triggers of cannabinoid release and short-term synaptic plasticity in cerebellar Purkinje neurons. J Neurosci 26:5428-5437.

Regehr WG, Carey MR, Best AR (2009) Activity-dependent regulation of synapses by retrograde messengers. Neuron 63:154-170.

Robbe D, Montgomery SM, Thome A, Rueda-Orozco PE, McNaughton BL, Buzsaki G (2006) Cannabinoids reveal importance of spike timing coordination in hippocampal function. Nat Neurosci 9:1526-1533.

Somogyi J, Baude A, Omori Y, Shimizu H, El Mestikawy S, Fukaya M, Shigemoto R, Watanabe M, Somogyi P (2004) GABAergic basket cells expressing cholecystokinin contain vesicular glutamate transporter type 3 (VGLUT3) in their synaptic terminals in hippocampus and isocortex of the rat. Eur J Neurosci 19:552-569.

Tanimura A, Yamazaki M, Hashimotodani Y, Uchigashima M, Kawata S, Abe M, Kita Y, Hashimoto K, Shimizu T, Watanabe M, Sakimura K, Kano M (2010) The endocannabinoid 2-arachidonoylglycerol produced by diacylglycerol lipase alpha mediates retrograde suppression of synaptic transmission. Neuron 65:320-327.

Varma N, Carlson GC, Ledent C, Alger BE (2001) Metabotropic glutamate receptors drive the endocannabinoid system in hippocampus. J Neurosci 21:RC188(1-5).

Vida I, Halasy K, Szinyei C, Somogyi P, Buhl EH (1998) Unitary IPSPs evoked by interneurons at the stratum radiatum-stratum lacunosummoleculare border in the CA1 area of the rat hippocampus in vitro. J Physiol 506:755-773.

Wilson RI, Nicoll RA (2001) Endogenous cannabinoids mediate retrograde signalling at hippocampal synapses. Nature 410:588-592.

Wilson RI, Kunos G, Nicoll RA (2001) Presynaptic specificity of endocannabinoid signaling in the hippocampus. Neuron 31:453-462.

Yoshida T, Fukaya M, Uchigashima M, Miura E, Kamiya H, Kano M, Watanabe M (2006) Localization of diacylglycerol lipase- $\alpha$ around postsynaptic spine suggests close proximity between production site of an endocannabinoid, 2-arachidonoyl-glycerol, and presynaptic cannabinoid $\mathrm{CB}_{1}$ receptor. J Neurosci 26:4740-4751. 